\title{
FATTY ACIDS OF THE BRAIN IN PHENYLKETONURIA*
}

\author{
J. Lindsley Foote $\dagger$ and Bernard W. AgranofF \\ Mental Health Research Institute and Department of Biological Chemistry, \\ University of Michigan, Ann Arbor, Michigan
}

(Received 3 February 1964)

\section{INTRODUCTION}

IN THE past several years, the nature of the enzymic defect associated with phenylketonuria (PKU) has been well defined (JERVIS, 1947; UDENFRIEND and BESSMAN, 1953; Wallace, Moldave and Meister, 1957; Mitoma, Auld and Udenfriend, 1957; KaUfman, 1961). However, a direct relationship between the absence of phenylalanine hydroxylase in the liver and mental deficiency remains to be demonstrated. Hypotheses relating the biochemical defect to the disease generally invoke competitive inhibition of an enzyme system by increased concentrations of one or more metabolites of the alternative pathways of phenylalanine metabolism (KNOX, 1960; PERRY, 1962).

One characteristic of PKU is the irreversibility of the mental defect when dietary therapy is instituted after infancy. These early years are a period of active myelination. The possibility that PKU involves abnormal lipid metabolism is strengthened by reports of demyelination associated with PKU (Alvord, STEvenson, Vogel and Engle, 1950; Scholz, 1957; Poser and Bogaert, 1959; Crome, Tymms and Woolf, 1962). Other cogent arguments for a lipid defect in this disease have been reviewed (KNOX, 1960, 1961). From the biochemical standpoint, a lipid disorder in PKU is suggested by the following:

1. Phenylacetic acid, a metabolite of phenylalanine, is present in increased amounts in PKU serum. The activation of phenylacetic acid to phenylacetyl CoA has been demonstrated in human liver (MoldAVE and MeISTER, 1957). More recently, acylation of ethanolamine with phenylacetic acid, presumably via the CoA derivative, has been demonstrated (Colodzin, BACHUR, WeISSBACH and UDENFRIEND, 1963).

2. The well known oxidation of $\omega$-phenyl fatty acids (KNOOP, 1904), together with the known reversibility of $\beta$-oxidation (LYNEN, 1955), suggests that a phenyl fatty acid derivative such as phenylacetyl CoA may be lengthened by addition of 2-carbon units.

3. Fatty acid synthesis via malonyl CoA requires an end group of acetyl CoA which can to some extent be substituted. For example, propionyl CoA results in the formation of odd-numbered fatty acids (HORNING, MARTIN, KARMEN and VAGELOS, 1961; Brady, Bradley and Trams, 1960; Vagelos et al., 1961; WaKil, 1961; HajRA and RADIN, 1962). Also terminal branched-chain fatty acids are formed from branchedchain precursors (LenNarz, 1961; Horning et al., 1961; Vagelos et al., 1961).

These observations suggested that in PKU, $\omega$-phenyl fatty acids are formed as a result of an elevated phenylacetate concentration in the body. The derived fatty acids

* Supported in part by Grant B3101, National Institute of Neurological Diseases and Blindness.

$\dagger$ Postdoctoral Training Fellow, USPHS, M7417.

Abbreviations used: PKU, phenylketonuria; GLC, gas-liquid chromatography; TLC, thin-layer chromatography; DMP, dimethoxypropane; DEGS, diethyleneglycol succinate polyester. 
might then form defective structural lipids or interfere with complex lipid synthesis and ultimately be reflected in abnormal function.

The present study was directed at testing this hypothesis. As an arbitrary criterion it was taken that a 1 per cent level of $\omega$-phenyl groups in brain fatty acids would constitute a sufficient amount to support the hypothesis. Techniques were developed for detection of $\omega$-phenyl groups at this level in biological material. $\omega$-Phenyl fatty acids were not detected in PKU or non-PKU brains.

\section{MATERIALS AND METHODS}

Materials. Diethyl ether, petroleum ether (Skellysolve B, b.p. 67-68 ${ }^{\circ}$ ), isopropenyl acetate (Carbide and Carbon Chemicals Co., New York), and 2-(2-ethoxyethoxy)ethanol (Matheson, Coleman and Bell, Norwood, Ohio) were redistilled before use. Benzoic acid, phenylacetic acid and phenylbutyric acid were recrystallized before use. Diazald ( $N$-methyl- $N$-nitroso-p-toluenesulphonamide) was obtained from Aldrich Chemical Co., Milwaukee. Methyl benzoate was purchased from Fisher Scientific Co., Pittsburgh, and gave a single peak on GLC. Standards for GLC were mixtures of commercial and synthetic methyl esters furnished by Dr. N. RADIN of this laboratory. For the unbranched, unsubstituted (normal) acids, the mixture included esters of $C_{14}$ through $C_{24}$ acids with the exception of $C_{21}$. The $\alpha$-acetoxy methyl ester mixture contained acids with chain lengths of $C_{18}$, $\mathrm{C}_{29}$, and $\mathrm{C}_{24}$. Florisil was obtained from the Floridin Co., Tallahassee, Florida. Other chemicals were analytical reagent grade.

TLC was done with silica gel G (Brinkmann Instruments Co., New York). Plates were developed in Skellysolve B-ether (3:1) and sprayed with aqueous alkaline bromthymol blue. Standards were authentic methyl stearate $\left(R_{f}=0.92\right)$, methyl $\alpha$-hydroxy stearate $\left(R_{f}=0.40\right)$, and cholesterol $\left(R_{f}=\right.$. $0 \cdot 18)$.

$\left[3{ }^{-14} \mathrm{C}\right]$ Phenylalanine and $\left[2-{ }^{14} \mathrm{C}\right]$ phenylacetate were purchased from New England Nuclear Corp., Boston.

The authors are indebted to Dr. R. AlLEN of the University of Michigan for a sample of frozen PKU brain (J.D., 18 yrs.) and for amino acid analyses, performed by Mr. R. SHAH. Two formalinfixed PKU brain specimens (V.N., 26 yrs. and W.J., 2.5 yrs.) were kindly supplied by Dr. G. A. JERVIS of Letchworth Village, Thiels, N.Y. The formalin-fixed brain from a case of maple syrup urine disease (C.D., 17 months) was obtained from Dr. W. A. HawK of the Cleveland Clinic. Other brains (L.B., 48 yrs, formalin-fixed and E.F., 33 yrs, fresh frozen) were obtained from the Department of Pathology, University of Michigan.

Isolation of fatty acids. One $\mathrm{g}$ of brain containing approximately equal amounts of white and grey matter is homogenized in $19 \mathrm{ml}$ of chloroform:methanol (2:1) and filtered through sintered glass with vacuum, and the residue is washed twice with $3 \mathrm{ml}$ of the same solvent. The total chloroform-methanol extract is washed with one-fifth its volume of water. The resulting lower layer is further washed with the same volume of water plus one-half this amount of methanol. The aqueous methanol upper layer is discarded. The lower phase is evaporated to near dryness on a rotary evaporator. To facilitate drying and to reduce splashing $10 \mathrm{ml}$ of absolute ethanol are added and the evaporation is continued to dryness.

Hydrolysis is carried out by refluxing the lipid fraction in $20 \mathrm{ml}$ of methanol and $4 \mathrm{ml}$ of conc. $\mathrm{HCl}$ for $6 \mathrm{hr}$ (HAJRA and RADIN, 1962), after which an equal volume of water is added. The cooled mixture is treated three times with $20 \mathrm{ml}$ portions of ether. The ether is evaporated under a stream of nitrogen, and $20 \mathrm{ml}$ of $95 \%$ ethanol and $1 \mathrm{ml}$ of $40 \% \mathrm{KOH}$ are added to the residue. This mixture is heated for $2 \mathrm{hr}$ at $80^{\circ}$ (AlBRINK, 1959) in a closed screw-cap test tube. Water (5 ml) is added, and the solution is treated three times with $10 \mathrm{ml}$ of Skellysolve $\mathrm{B}$. Concentrated $\mathrm{HCl}$ is added to $\mathrm{pH} 1$ $(\mathrm{pH}$ paper) and the fatty acids are extracted with ether.

Oxidation of fatty acids. Fatty acids from $0.5 \mathrm{~g}$ of brain in ether are dried with a stream of $\mathrm{N}_{2}$ in a one-piece refluxing apparatus consisting of an $18 \times 70 \mathrm{~mm}$ test tube sealed to a small condenser. One millilitre of water, $0.2 \mathrm{ml}$ of $5 \mathrm{~N}-\mathrm{KOH}$, and $1 \mathrm{ml}$ of $0.3 \mathrm{M}-\mathrm{KMnO}_{4}$ are added. The mixture is heated to reflux with magnetic stirring for $4 \mathrm{hr}$. Additional $1 \mathrm{ml}$ portions of $\mathrm{KMnO}_{4}$ are added at $15,30,60,90$ and $150 \mathrm{~min}$ to maintain the purple colour.

The cooled mixture is acidified to $\mathrm{pH} 1$ (pH paper) with conc. $\mathrm{H}_{2} \mathrm{SO}_{4}$. Sufficient sodium bisulphite is added to reduce the $\mathrm{MnO}_{2}$ and excess $\mathrm{KMnO}_{4}$. Benzoic acid from the oxidation of $\omega$ phenyl fatty acids is extracted from the clear acidic solution with three $5 \mathrm{ml}$ portions of ether. The ether solution is treated three times with $5 \mathrm{ml}$ of $1 \mathrm{~N}-\mathrm{KHCO}_{3}$. The aqueous extract is acidified with conc. $\mathrm{HCl}$ and treated three times with $5 \mathrm{ml}$ of ether. This final ether solution is dried over sodium sulphate. The sodium sulphate is washed with ether, and the combined ether solutions are evaporated to about $0.5 \mathrm{ml}$. 
Methylation and gas-liquid chromatography of benzoate. The ether solution containing benzoic acid, along with other acidic materials from the oxidation mixture, is methylated with diazomethane (SCHLENK and Gellerman, 1960). DMP, conveniently used for fatty acid esterification (Kishimoto and RADIN, 1963), could not be used here because it did not methylate benzoic acid quantitatively with the conditions used. GLC was performed on a flame ionization gas chromatograph (Model 609, F and M Scientific Corp., Avondale, $\mathrm{Pa}$.). A portion of the resulting esters is chromatographed on a $36 \times 1 / 8$ in. o.d. column containing 15 per cent DEGS on Gas Chrom Z (Applied Science Laboratories, Inc., State College, Pa.). One minute after injection into the column (pre-heated to $50^{\circ}$ ), the temperature is raised $2 \cdot 3^{\circ}$ per min. The retention time of authentic methyl benzoate is approximately $7 \mathrm{~min}$.

Methylation and GLC of fatty acids. A portion of the brain total fatty acid fraction was methylated with DMP. The normal and hydroxy esters were separated by TLC or a Florisil column (HAJRA and RADIN, 1962). The hydroxy acid methyl esters were acetylated with isopropenyl acetate (HAGemeYer and Hull, 1949; Kishimoto and RAdin, 1963) prior to GLC. Radioactivity was measured with a Tri-Carb scintillation counter (Packard Instrument Co., LaGrange, Ill.). Samples were dissolved in $15 \mathrm{ml}$ of toluene containing 0.4 per cent 2,5-diphenyloxazole and 0.01 per cent 1,4-bis-2-(5-phenyloxazolyl)-benzene. All samples were corrected for quenching.

\section{RESULTS}

Recovery of benzoate from oxidation mixtures. Recovery oxidation experiments were carried out with phenylbutyric acid, phenylacetic acid, and palmitic acid as

TABLE I,-RECOVERY OF BENZOIC ACID FROM THE OXIDATION OF PHENYL FATTY ACIDS

\begin{tabular}{|c|c|c|}
\hline Method & Mixture oxidized & $\%$ Recovered \\
\hline Gravimetric $^{\mathbb{a}}$ & phenylacetic acid, $524 \mu$ moles & 51 \\
\hline Spectrophotometric ${ }^{b}$ & phenylbutyric acid, $0.94 \mu$ mole & 88 \\
\hline Spectrophotometric & $\begin{array}{l}\text { phenylbutyric acid, } 0.94 \mu \text { mole } \\
+ \text { palimitic acid, } 105 \mu \text { moles }\end{array}$ & 78 \\
\hline GLC & phenylbutyric acid, $0.94 \mu$ mole & 75 \\
\hline GLC & $\begin{array}{l}\text { phenylbutyric acid, } 0.94 \mu \text { mole } \\
+ \text { palimitic acid, } 144 \mu \text { moles }\end{array}$ & 79 \\
\hline GLC & $\begin{array}{l}\text { phenylbutyric acid, } 1.04 \mu \text { moles } \\
+ \text { brain fatty acids, } 35.2 \mathrm{mg}\end{array}$ & 89 \\
\hline
\end{tabular}

a The ether extract from an oxidation mixture was dried, and the benzoic acid weighed. Yield $=32.7 \mathrm{mg}$; melting point, $113-120^{\circ}$, mixed melting point $117-122^{\circ}$; melting point after recrystallization from water, $121-122^{\circ}$.

${ }^{b}$ A portion of the extracted oxidation product in $3 \mathrm{ml}$ of methanol with $0.01 \mathrm{ml}$ of $12 \mathrm{~N}-\mathrm{HCl}$ was read against a methanol-HCl blank in a $10 \mathrm{~mm}$ quartz cuvette at $272 \mathrm{~m} \mu, \varepsilon_{272}=890$ (for phenylbutyrate, $\varepsilon_{272}=29$ ).

model compounds. Best results for the oxidation of phenylbutyric acid were obtained by refluxing the compound in slightly more alkaline $\mathrm{KMnO}_{4}$ than the 6 moles theoretically required for oxidation to benzoic acid and $\mathrm{CO}_{2}$. When palmitic acid was added to the oxidation mixture, somewhat more than the above amount of $\mathrm{KMnO}_{4}$ was required for optimal conversion of phenylbutyric acid to benzoic acid. However, relatively little $\mathrm{KMnO}_{4}$ was taken up by palmitate; this result indicates a preferential oxidation alpha to the phenyl group. This permitted a fairly complete oxidation of phenylbutyrate in the presence of 100 -fold excess of palmitate. Sufficient $\mathrm{KMnO}_{4}$ was added to maintain a purple colour in these experiments as well as those involving brain fatty acid and total lipid extracts.

Yields of benzoate from the oxidation of phenylbutyrate ranged from 75 to 89 per cent when analysed by GLC (Table 1). The range of recovery reflects variable losses during the oxidation. While ultraviolet analysis of oxidation mixtures gives comparable results, excessive amounts of chromogenic materials are introduced when tissue extracts are oxidized. While additional peaks were observed on GLC, 
particularly when the oxidation mixtures contained fatty acids, they were not in the region of methyl benzoate and did not interfere with its measurement.

Oxidation studies with human brain. PKU (V.N., W.J. and J.D.) and non-PKU (L.B.) brains were analysed by the above procedure. No trace of methyl benzoate was found; this result indicates the presence of less than 1 per cent $\omega$-phenyl fatty acid in the fatty acid fraction of these brains.

The possibility was considered that $\omega$-phenyl groups are present in other lipid fractions. $\omega$-Phenylalkylamines and ethers are possible lipids which would not be found in the fatty acid fraction. Chloroform-methanol extracts were oxidised with $\mathrm{KMnO}_{4}$. These crude extracts consumed more $\mathrm{KMnO}_{4}$ (about $6.4 \mu$ moles per $\mathrm{g}$ of brain) than the fatty acid fractions ( $1.8 \mu$ moles per $\mathrm{g}$ of brain). An additional $0.1 \mathrm{ml}$ of $5 \mathrm{~N}-\mathrm{KOH}$ was added after $2 \mathrm{hr}$ of reflux. Ether extracts from the oxidation mixture were methylated and subjected to GLC. Two formalin-fixed brains (V.N. and L.B.) yielded no methyl benzoate. The frozen non-PKU (E.F.) and frozen PKU (J.D.) brains contained $327 \mu \mathrm{g}$ and $280 \mu \mathrm{g}$ of methyl benzoate, respectively, per $\mathrm{g}$ of brain. Subsequently, the aqueous layer following acid hydrolysis of lipids from each of these brains was hydrolysed for $24 \mathrm{hr}$ in $8 \mathrm{~N}-\mathrm{HCl}$. The amino acid analyses of this fraction indicated that at least 42 per cent of the methyl benzoate from non-PKU brain and 70 per cent of the methyl benzoate from the PKU brain could be attributed to phenylalanine in proteolipid.

In the light of all of the foregoing results, it is not probable that accumulation of $\omega$-phenyl lipids is the cause of the reported demyelination or of the related mental deficiency in PKU.

Fatty acid distribution in non-PKU and PKU brain. TLC of the methylated fatty acid preparations showed only two major spots corresponding to normal and $\alpha$ hydroxy methyl esters. Occasionally, a faint spot was seen which had the $R_{f}$ of cholesterol. The use of DEGS for the GLC of the normal ester fraction permitted fairly complete resolution of oleic and stearic acid. 20:4 and 22:5 were not separated from 22:0 and 24:0 respectively (JoHNSTON and Kummerow, 1960). In addition, $22: 4$ was not completely separated from $24: 0+22: 5$. The general distribution pattern of fatty acids for brain is similar to the results reported for human brain by JOHNSTON and Kummerow (1960) although there is preliminary evidence suggesting a relative decrease in the ratio of oleic acid to stearic acid in PKU brain. No evidence of branched-chain fatty acids was found in the maple syrup disease brain. A unique fatty acid which accumulates in only one class of lipids could go undetected.

The distribution of hydroxy acids does not indicate any pronounced differences between non-PKU and PKU brains. In each brain the $\mathrm{C}_{24}$ hydroxy acids comprised 50-58 per cent of the total hydroxy acids by weight with 8-17 per cent distributed in each of the $\mathrm{C}_{23}$ and $\mathrm{C}_{25}$ fractions.

In vivo studies with rat brain. Experiments were performed to measure the possible incorporation of labelled phenylalanine and phenylacetic acid into fatty acids. Fifteen-day-old rats were injected with $12.5 \mu \mathrm{C}(0.6 \mathrm{mg})$ of $\left[3-{ }^{14} \mathrm{C}\right]$ phenylalanine $\mathrm{HCl}$ either intraperitoneally or intracranially. The animals were sacrificed after $19 \mathrm{hr}$ and the fatty acids were extracted from brain and counted. In each case, about 20,000 disintegrations/min were obtained. GLC indicated that most of the activity was in palmitic acid. $\mathrm{KMnO}_{4}$ oxidation released almost all of the radioactivity as $\mathrm{CO}_{2}$. These results are compatible with oxidation of phenylalanine in the liver regardless of the 
route of injection, and subsequent incorporation of labelled acetate formed into fatty acids in the brain. Intracranial injection of a similar amount of sodium $\left[2-{ }^{14} \mathrm{C}\right]-$ phenylacetate resulted in the incorporation of one-tenth the amount of radioactivity into total fatty acids observed with phenylalanine. In each instance, radioactivity amounting to about one-half that in the fatty acids was found in the non-saponifiable lipid fraction.

\section{DISCUSSION}

The combined $\mathrm{KMnO}_{4}$ oxidation, esterification and GLC appear sufficiently sensitive to detect small amounts of substances that yield benzoate upon oxidation. For example, $1 \mathrm{~g}$ of brain yields about $100 \mu$ moles of fatty acids, and $1 \mu$ mole of benzoic acid could easily be detected in the oxidation products.

Analytical studies of human brain as well as radioisotopic experiments in rats gave no evidence for the possibility that $\omega$-phenyl fatty acids are present in mammalian brain. The report of Bentley, Ramsey, Springer, DialameH and Olsen (1961) that radioactivity from phenylalanine is incorporated into coenzyme $Q$ may partially explain the finding that radioactivity is incorporated into the non-saponifiable fraction.

\section{SUMMARY}

A method is described for the determination of $\omega$-phenyl fatty acids in biological material. The method was employed to establish whether or not the high concentration of phenylalanine or its metabolites causes the synthesis of abnormal lipids such as $\omega$-phenyl fatty acids which in turn might be related to the mental retardation of phenylketonuria. No $\omega$-phenyl fatty acids were found in three brains from phenylketonuric individuals.

\section{REFERENCES}

Albrink M. J. (1959) J. Lipid Res. 1, 53.

Alvord E. C. Jr., Stevenson L. D., Vogel F. S. and Engle R. L. Jr. (1950) J. Neuropath. exp. Neurol. 9, 298.

Bentley R., Ramsey V. G., Springer C. M., Dialameh G. H. and Olsen R. E. (1961) Biochem. biophys. Res. Commun. 5, 443.

Brady R. O., Bradley R. M. and Trams E. G. (1960) J. biol. Chem. 235, 3093.

Colodzin M., Bachur N. R., Weissbach H. and Udenfriend S. (1963) Biochem. biophys. Res. Commun. 10, 165.

Crome L., Tymms V. and Woolf L. I. (1962) J. Neurol. Neurosurg. Psvchiat. 25, 143.

Hagemeyer H. J. Jr. and Hull C. D. (1949) Ind. Eng. Chem. 41, 2920.

HAJRA A. K. and RADIN N. S. (1962) J. Lipid Res. 3, 327.

Horning M. G., Martin D. B. Karmen A. and Vagelos P. R. (1961) J. biol. Chem. 236, 669.

Jervis G. A. (1947) J. biol. Chem. 169, 651 .

Johnston P. V. and Kummerow F. A. (1960) Proc. Soc. exp. Biol. (N.Y.) 104, 201.

KaufMan S. (1961) In Chemical Pathology of the Nervous System (Edited by Folch-PI J.) p. 51, Pergamon Press, Oxford.

Kishimoto Y. and Radin N. S. (1963) J. Lipid Res. 4, 130.

KNOOP F. (1904) Beitr. chem. Physiol. Path. 6, 150.

KNOX W. E. (1960) In Metabolic Basis of Inherited Disease (Edited by STANBURY J. B., WYNGAARDEN J. B. and Fredrickson D. S.) p. 321, McGraw-Hill, New York.

Knox W. E. (1961) In Chemical Pathology of the Nervous System (Edited by FolCh-PI J.) p. 32, Pergamon Press, Oxford.

LeNNARz W. J. (1961) Biochem. biophys. Res. Commun. 6, 112.

LYNEN F. (1955) Ann. Rev. Biochem. 24, 653.

Miloma C., Auld R. M. and Udenfriend S. (1957) Proc. Soc. exp. Biol. (N. Y.) 94, 634.

Moldave K. and Meister A. (1957) J. biol. Chem. 229, 463.

Perry T. L. (1962) Science 136, 879.

Poser C. M. and Bogaert L. van (1959) Brain 82, 1. 
Schlenk H. and Gellerman J. L. (1960) Analyt. Chem. 32, 1412.

Scholz W. (1957) L'Encephale 46, 668.

Udenfriend S. and Bessman S. P. (1953) J. biol. Chem. 203, 961.

Vagelos P. R., Martin D. B., Karmen A. and Horning M. G. (1961) V Int. Congr. Biochem. Symposium No. VII, p. 104.

WAKIL S. J. (1961) J. Lipid Res. $2,1$.

Wallace H. W., Moldave K. and Meister A. (1957) Proc. Soc. exp. Biol. (N.Y.) 94, 632. 